\title{
Epidemiology and visual outcomes of ocular injuries in a low resource country
}

\author{
Emmanuel K Abu, ${ }^{1}$ Stephen Ocansey, ${ }^{1}$ Jennifer A Gyamfi, ${ }^{1}$ Michael Ntodie, ${ }^{1,2}$ Enyam KA Morny ${ }^{1}$
}

\section{Department of Optometry and Vision Science, School of Allied Health Sciences, University of Cape Coast, Ghana.}

2. Optometry and Vision Science Group, School of Biomedical Sciences, Ulster University, Coleraine, BT52 1SA, UK.

\begin{abstract}
:
Background: Ocular injury is a major cause of ocular morbidity and unilateral visual impairment and represents a considerable public health concern especially in low resource societies.

Objective: To evaluate the epidemiology and visual outcomes of ocular injuries in southern Ghana

Methods: A retrospective hospital-based case series was conducted. Information on new cases of ocular injuries were retrieved and parameters including time between injury occurrence and reporting to the clinic, presenting visual acuity (VA), and the best corrected final VA were investigated and visual outcomes were assessed

Results: Most (50.2\%) of the patients reported to the hospital after a day of sustaining an ocular injury; workplace injuries, older patients and farm-related injuries were most likely to report after a day of sustaining an injury. A significant proportion (40.4\%) of patients reported with good presenting vision (6/6-6/18) which increased to $56.7 \%$ after treatment; $45.3 \%$ of patients reported with visual impairment $(<6 / 18)$ and reduced to $42.4 \%$ after treatment. Farming (AOR $=4.5, \mathrm{p}=0.02)$, reporting after a day of sustaining injury ( $\mathrm{AOR}=78, \mathrm{p}<0.001$ ), workplace injuries $(\mathrm{AOR}=3.1, \mathrm{p}=0.007$ ) and roadside injuries $(\mathrm{AOR}=3.1, \mathrm{p}=0.02$ ) were associated with poor visual outcomes. Initial VA $6 / 18$ or better was the highest predictor of good visual outcome
\end{abstract}

Conclusion: There is a shift in the pattern of ocular injury occurrence from work-related to home- related.

Keywords: Epidemiology; visual outcome; ocular injuries; incidence; Ghana.

DOI: https://doi.org/10.4314/ahs.v20i2.31

Cite as: Abu EK, Ocansey S, Gyamfi JA, Ntodie M, Morny EKA. Epidemiology and visual outcomes of ocular injuries in a low resource country. Afri Health Sci. 2020; 20(2): 779-788. bttps://doi.org/10.4314/abs.v20i2.31

\section{Introduction}

Worldwide, ocular injuries have become a public health concern as they constitute a preventable cause of ocular morbidity and unilateral visual impairment, ${ }^{1,2}$ particularly in developing countries. ${ }^{3,4}$ Not only do ocular injuries create significant morbidity but they also impact the socioeconomic status of a country greatly. ${ }^{5,6}$ Ocular injuries are known to be more frequent in children and the younger productive population ${ }^{7,8,9}$, raising concerns of lost productivity and the burden of visual impairment associated with disability-adjusted life years. Each year, around 55 million eye injuries restrict activities for more than a day, ${ }^{5}$ emphasizing the socioeconomic bur-

\section{Corresponding author: \\ Emmanuel K Abu, \\ Department of Optometry and Vision Science, \\ School of Allied Health Sciences, \\ University of Cape Coast, PMB, Cape Coast, Ghana. \\ Tel. +233244990030 \\ Email: eabu@ucc.edu.gh}

den of ocular injuries in societies they occur. In low and middle income communities, lack of or inadequate health facilities resulting in late presentation to the major referral hospitals complicates these cases. ${ }^{10}$ In some instances patients resort to the use of unorthodox traditional health care practices which lead to poor visual outcomes. ${ }^{11}$ The pattern and epidemiological characteristics of ocular injuries differ from one country to another because ocular injuries reflect differing levels of socioeconomic status pertaining to access to health care, safety standards at work places and levels of industrialisation. ${ }^{7}$ In industrialised societies, for instance, industrial related activities remain the most common cause of ocular injuries whereas in most poor rural communities the main cause is farm related. ${ }^{8,11,12}$

Visual outcomes following injuries depend on a number of factors such as the agent causing the injury, type of ocular injury, places where the injuries occur, the time interval between injury occurrence and reporting to the hospital and the management protocol administered at the hospital. ${ }^{13-16}$ The economic burden associated with 
ocular injury especially regarding its preponderance in children and productive middle-age men, and the cost of treatment and rehabilitation services places a compelling need for making preventive measures a priority. The first step in prevention is to understand the local causes and patterns of ocular injuries by way of accurate data to guide the development of local prevention interventions, such as protective eyewear in the workplace, legislation and enforcement of the use of seat belts. ${ }^{10}$ Many developed countries have implemented strategies peculiar to their socioeconomic backgrounds in order to reduce this public health menace. For instance, the US has an established Work-Related Injury Statistics Query System to monitor and report such injuries. ${ }^{17}$ Again in the US, there exist industrial safety organizations such as the Wise Owl clubs whose members are employees who have had one or both eyes saved from a serious injury by the use of protective lenses. ${ }^{18}$

In low resource societies like Ghana, there is dearth of information on ocular injuries as there is no enforcement on mandatory reporting of ocular injuries by employers or health care providers. ${ }^{10}$ Therefore, epidemiological studies of this nature are necessary to provide information regarding ocular injuries and their impact on ocular morbidity and visual impairment. The purpose of this study was to evaluate the epidemiological characteristics and visual outcomes of ocular injuries at a tertiary teaching hospital in Southern Ghana. This report intends to identify the risk factors associated with poor visual outcomes to enable the planning of local preventive strategies and to optimize appropriate intervention capacities.

\section{Methods}

\section{Study design and subjects}

A one-year retrospective hospital-based case series was conducted at a tertiary teaching hospital located in Southern Ghana. The eye care work force at this referral eye centre consisted of ophthalmologists, optometrists, and ophthalmic nurses. The study population comprised all new ocular injury patients who reported to the eye clinic of the Cape Coast teaching hospital from January 2014 to December 2014. The study was conducted in accordance with the tenets of the Declaration of Helsinki regarding research involving human subjects. Ethical clearance was obtained from the Institutional Review Board of the University of Cape Coast.
Permission was also obtained from the teaching hospital prior to the commencement of the study. All folders of ocular injury cases that were reported within the time frame were retrieved, reviewed and the following variables recorded: the patient's identification number, age, gender, occupation, admission status, eye involved, type of injury, ocular structure involved, place of injury, agent of injury, treatment modality, time interval between occurrence of injury and presentation to the hospital, presenting visual acuity, and the best corrected final visual acuity at the last follow-up.

\section{Data collection}

The data were collected using pre-tested and validated data collection forms. Actual visual outcomes (using visual acuities) rather than predictive visual outcomes (using the ocular trauma scores) were assessed in this study. Visual outcomes were assessed based on the post-treatment best corrected final visual acuities (BCVA) (at the last follow-up) and categorized into good outcome (6/6-6/18), borderline outcome (6/24$6 / 60)$ and poor outcome $(<6 / 60){ }^{8}$ The visual acuities were also categorized using the International Classification of Diseases criteria (WHO, 2005). ${ }^{20}$

\section{Statistical analysis}

The data collected were analysed using the SPSS statistical software. Chi-square test was performed to assess differences in categorical variables between two or more groups; the Fisher's exact test was used where the proportions were lower than five counts. The independent-samples t-test was used to compare the means of ages between two or more groups. The logistic and linear regression analyses were performed to predict the associations between dependent and independent variables. A two-tailed p-value less than 0.05 was considered statistically significant.

\section{Results \\ Demographic Characteristics of Participants}

A total of 6050 new cases of eye diseases were reported to the eye clinic of the teaching hospital from $1^{\text {st }}$ January to $31^{\text {st }}$ December, 2014. Out of this, 203(3.4\%) were ocular injury cases and were included in the analysis. The mean age of ocular injury patients was $29.2 \pm$ 19.2 years with a male to female ratio of 1.7:1. Table 1 shows the demographic characteristics of the participants. 
Table 1: Demographic Characteristics of Ocular Injury Patients

\begin{tabular}{lc}
\hline Demographics & $\mathrm{n}(\%)$ \\
\hline Gender & \\
Male & $128(63.1)$ \\
Female & $75(36.9)$ \\
Total & $203(100)$ \\
Age range & \\
$00-09$ & $35(17.2)$ \\
$10-19$ & $35(17.2)$ \\
$20-29$ & $41(20.2)$ \\
$30-39$ & $39(19.2)$ \\
$40-49$ & $17(8.4)$ \\
$50-59$ & $19(9.4)$ \\
$60-69$ & $8(3.9)$ \\
$70-79$ & $9(4.4)$ \\
Total & $203(100)$ \\
Occupation & \\
Children/students/pupils & $85(41.9)$ \\
Farming & $32(15.8)$ \\
Trading & $32(15.8)$ \\
Civil/public servant & $27(13.3)$ \\
Retired & $12(5.9)$ \\
Artisans & $9(4.4)$ \\
Fishing & $2(1.0)$ \\
Total & $203(100)$ \\
\hline
\end{tabular}

\section{Characteristics of Ocular Injuries Reported}

The records revealed that most of the patients 102 $(50.2 \%)$ reported to the hospital after a day (24 hours) of sustaining an ocular injury and for 21 patients it could not be inferred from their folders when they reported. A high proportion $75(36.9 \%)$ of ocular injuries occurred at home but information on the agent or source of injury was not available for 59(29.1\%) cases.
Ocular injuries were mostly mechanical globe injuries 168(82.8\%) comprising 110(65.5\%) closed globe and $58(34.5 \%)$ open globe injuries. Non-globe injuries were $26(12.8 \%)$, the majority $25(96.2 \%)$ being lid injuries and one $(3.8 \%)$ case of an orbital fracture. There were $9(4.4 \%)$ cases of non-mechanical globe injuries mostly chemical $8(88.9 \%)$ and one (11.1) thermal burn. The characteristics of ocular injuries are presented in table 2.

Table 2: Characteristics of Ocular Injuries Reported

\begin{tabular}{lc}
\hline Characteristic & $\mathbf{n}(\%)$ \\
\hline Type of injury & \\
Mechanical globe & $168(82.8)$ \\
Non-mechanical globe & $9(4.4)$ \\
Non-globe & $26(12.8)$ \\
Time of reporting & \\
After 24hrs & $102(50.2)$ \\
Within 24hrs & $80(39.4)$ \\
Not recorded & $21(10.3)$ \\
Place of injury & \\
Home & $75(36.9)$ \\
Work & $56(27.6)$ \\
School & $30(14.8)$ \\
Road & $29(14.3)$ \\
Not recorded & $8(3.9)$ \\
Sports/recreation & $5(2.5)$ \\
Agent of injury & \\
Blunt & $83(40.9)$ \\
Not recorded & $59(29.1)$ \\
Sharp & $41(20.2)$ \\
Projectile & $10(4.9)$ \\
Chemical & $9(4.4)$ \\
Thermal/radiation & $1(0.5)$ \\
\hline
\end{tabular}


Table 3 presents the associations between patient/injury characteristics and time of reporting to the hospital after sustaining an injury. The majority of workplace ocular injuries reported late (after a day) and occupations that are usually associated with low levels of education such as farming, trading and artisanship were the most likely to report late (Table 3).

Table 3: Relation between patient/injury characteristics and time of reporting to the hospital after sustaining an injury

\begin{tabular}{lccccc}
\hline Characteristic & \multicolumn{2}{c}{ Time of reporting to the hospital } & Total & $\chi^{2}$ & p-value \\
\cline { 2 - 3 } & Early (within 24 hours) & Late (after 24 hours) & & & \\
\hline Gender & $51(44.7)$ & $63(55.3)$ & 114 & 0.08 & 0.88 \\
Male & $29(42.4)$ & $39(57.4)$ & 68 & & \\
Female & & & 28.6 & $<0.001$ \\
Occupation & $17(73.9)$ & $6(26.1)$ & 23 & & \\
Public/civil servant & $7(58.3)$ & $5(41.7)$ & 12 & & \\
Retired & $40(52.6)$ & $36(47.4)$ & 76 & & \\
Children/Student/pupil & $1(50.0)$ & $1(50.0)$ & 2 & & \\
Fishing & $3(33.3)$ & $6(66.7)$ & 9 & & \\
Artisans & $9(30.0)$ & $21(70.0)$ & 30 & & \\
Trading & $3(10.0)$ & $27(90.0)$ & 30 & & \\
Farming & & & & \\
Type of injury & $8(88.9)$ & $1(11.1)$ & 9 & & \\
Non-mechanical globe & $16(69.6)$ & $7(30.4)$ & 23 & & \\
Non-globe & $56(37.3)$ & $94(62.7)$ & 150 & & \\
Mechanical globe & & & & \\
Place of injury & $5(100.0)$ & $0(0.0)$ & 5 & \\
Sports/recreation & $41(64.1)$ & $23(35.9)$ & 64 & & \\
Home & $12(44.4)$ & $15(55.6)$ & 27 & \\
Road & $10(35.7)$ & $18(64.3)$ & 28 & & \\
School & $10(19.6)$ & $41(80.4)$ & 51 & \\
Work & & & & \\
Agent of injury & $9(100.0)$ & $0(0.0)$ & 9 & \\
Chemical & $17(44.7)$ & $21(55.3)$ & 38 & \\
Sharp & $29(40.8)$ & $42(59.2)$ & 71 & \\
Blunt & $3(33.3)$ & $6(66.7)$ & 9 & \\
Projectile & $0(0.0)$ & $1(100.0)$ & 1 & \\
Thermal/radiation & & & & \\
\hline
\end{tabular}

Again, younger patients reported earlier (mean age: 24.6 all age categories, road injuries occurred mostly among \pm 14.9 years) than older patients (mean age: $33.0 \pm 22.1$ the productive population while workplace injuries ocyears $)(F=8.5, p=0.004)$. Home injuries occurred in curred in all age categories except in children younger than ten years (Table 4).

Table 4: Association between the ages of participants and place of ocular injury occurrence

\begin{tabular}{lcccccccccc}
\hline & \multicolumn{1}{c}{ Age range of participants } \\
\cline { 2 - 11 } Place of injury & $0-9$ & $10-19$ & $20-29$ & $30-39$ & $40-49$ & $50-59$ & $60-69$ & $70-79$ & & Total \\
\hline Home & 19 & 12 & 14 & 13 & 8 & 4 & 1 & 4 & 26.5 & 75 \\
Work & 0 & 3 & 10 & 15 & 7 & 11 & 5 & 5 & 43.0 & 56 \\
School & 11 & 11 & 8 & 0 & 0 & 0 & 0 & 0 & 12.7 & 30 \\
Sports/recreatio & 1 & 1 & 3 & 0 & 0 & 0 & 0 & 0 & 18.6 & 5 \\
$\mathrm{n}$ & & & & & & & & & & \\
Road & 1 & 6 & 5 & 11 & 2 & 3 & 1 & 0 & 30.8 & 29 \\
Total & 32 & 33 & 40 & 39 & 17 & 18 & 7 & 9 & 29.5 & $195+$ \\
\hline
\end{tabular}

tPlace of injury could not be determined for 8 patients 


\section{Assessment of visual outcomes of patients}

Eighty-two (40.4\%) patients reported with initial good vision (VA of 6/6- 6/18) and for 29(14.3\%) patients initial visual acuity was not determined. After treatment of the injuries and based on the final BCVA (at last follow-up), 115 (56.7\%) of the patients had good visual outcomes. According to the International Classification of Diseases (ICD) criteria, 82(40.4\%) patients reported with normal vision which increased to $115(56.7 \%)$ after treatment while $92(45.3 \%)$ reported with visual impairment (including blindness) which reduced to 86(42.4\%) after treatment. Thus, there was an improvement in visual acuity of $16.3 \%$ of the patients following treatment. Table 5 shows the visual acuities of patients before and after treatment.

Table 5: Visual acuities of patients before and after treatment

\begin{tabular}{lcc}
\hline Classification of Vision & Initial VA & Final BCVA \\
\hline Normal vision/good outcome $(6 / 6-6 / 18)$ & $82(40.4)$ & $115(56.7)$ \\
Moderate impairment/borderline outcome $(<6 / 18-6 / 60)$ & $30(14.8)$ & $32(15.8)$ \\
Severe impairment/poor outcome $(<6 / 60)$ & $62(30.5)$ & $54(26.6)$ \\
VA not taken & $29(14.3)$ & $2(1.0)$ \\
Total & $203(100.0)$ & $203(100.0)$ \\
\hline
\end{tabular}

${ }^{\S}$ VA: visual acuity; "BCVA: best corrected visual acuity

Associations between patient/injury characteristics and visual outcomes

There was no significant difference between gender and visual outcome of ocular injury $\left(\chi^{2}=1.3, \mathrm{p}=0.56\right)$. However, there were significant differences between visual outcomes and other characteristics. For instance, ocular injuries that occurred during sports or recreation resulted in the best visual outcomes $5(100 \%)$, followed by injuries that occurred at homes 53(71.6\%). Regarding the type of ocular injuries, mechanical globe injuries were more devastating, accounting for all cases of poor visual outcomes in that category. Also, younger patients (mean age: $27.15 \pm 16.1$ years) had better visual outcomes after suffering an ocular injury compared to older patients (mean age: $32.22 \pm 22.6$ years) $(\mathrm{F}=2.7, \mathrm{p}=$ 0.04). Table 6 shows the relationship between patient/ injury characteristics and visual outcomes. 
Table 6: Associations between patient/injury characteristics and visual outcome

\begin{tabular}{|c|c|c|c|c|c|c|}
\hline \multirow[t]{2}{*}{ Characteristic } & \multicolumn{3}{|c|}{ Visual outcome } & \multirow[t]{2}{*}{ Total } & \multirow[t]{2}{*}{$\chi^{2}$} & \multirow[t]{2}{*}{ p-value } \\
\hline & Good & Borderline & Poor & & & \\
\hline Gender & & & & & 1.2 & 0.56 \\
\hline Male & $73(57.5)$ & $22(17.3)$ & $32(25.2)$ & 127 & & \\
\hline Female & $43(58.1)$ & $9(12.2)$ & $22(29.7)$ & 74 & & \\
\hline Time of reporting & & & & & 76.1 & $<0.001$ \\
\hline Within 24hrs & $73(92.4)$ & $5(6.3)$ & $1(1.3)$ & 79 & & \\
\hline After $24 \mathrm{hrs}$ & $29(28.4)$ & $22(21.6)$ & $51(50)$ & 102 & & \\
\hline Occupation & & & & & 22.0 & 0.03 \\
\hline Fishing & $1(50)$ & $1(50)$ & $0(0)$ & 2 & & \\
\hline Public/civil servant & $21(77.8)$ & $2(7.4)$ & $4(14.8)$ & 27 & & \\
\hline Student/pupil & $53(63.9)$ & $12(14.5)$ & $18(21.7)$ & 83 & & \\
\hline artisans & $5(55.6)$ & $2(22.2)$ & $2(22.2)$ & 9 & & \\
\hline Retired & $8(66.7)$ & $0(0)$ & $4(33.3)$ & 12 & & \\
\hline Trading & $19(52.8)$ & $5(13.9)$ & $12(33.3)$ & 36 & & \\
\hline Farming & $9(28.1)$ & $9(28.1)$ & 14(43.8) & 32 & & \\
\hline Type of Injury & & & & & 21.1 & 0.001 \\
\hline Mechanical Globe & $84(50.6)$ & $28(16.9)$ & $54(32.5)$ & 166 & & \\
\hline Non-mechanical Globe & $8(88.9)$ & $1(11.1)$ & $0(0)$ & 9 & & \\
\hline Non-globe & $24(92.3)$ & $2(7.7)$ & $0(0)$ & 26 & & \\
\hline Place of injury & & & & & 19.9 & 0.01 \\
\hline Sports/recreation & $5(100)$ & $0(0)$ & $0(0)$ & 5 & & \\
\hline Home & $53(71.6)$ & $9(12.2)$ & $12(16.2)$ & 74 & & \\
\hline School & $17(58.6)$ & $6(20.7)$ & $6(20.7)^{\prime}$ & 29 & & \\
\hline Road & $16(55.2)$ & $2(6.9)^{\prime}$ & $11(37.9)$ & 29 & & \\
\hline Work & $23(41.1)$ & $12(21.4)$ & $21(37.5)$ & 56 & & \\
\hline Agent of injury & & & & & 26.5 & 0.001 \\
\hline Chemical & $9(100)$ & $0(0.0)$ & $0(0.0)$ & 9 & & \\
\hline Blunt & $51(63)$ & $15(18.5)$ & $15(18.5)$ & 81 & & \\
\hline Sharp & $18(43.9)$ & $5(21.2)$ & $18(43.9)$ & 41 & & \\
\hline Projectile & $3(30.0)$ & $1(10.0)$ & $6(60)$ & 10 & & \\
\hline Thermal/radiation & $0(0.0)$ & $1(100.0)$ & $0(0.0)$ & 1 & & \\
\hline
\end{tabular}

From table 6, patient or injury characteristics with significant differences within groups by the chi-square analysis were selected for a multivariate logistic regression analysis to predict their relative associations with visual outcomes as shown in table 7. Open globe injuries, farming and reporting late to the hospital (after a day) were risk factors for poor visual outcomes or severe visual impairment (table 7).

Table 7: Multivariate logistic regression analysis between characteristics of ocular injuries and visual outcome

\begin{tabular}{lcccc}
\hline Characteristic & $\begin{array}{c}\text { Number } \\
\text { reported }\end{array}$ & $\begin{array}{c}\text { Number with poor visual } \\
\text { outcome }\end{array}$ & AOR $^{\ddagger}$ & p-value \\
\hline Occupation & 27 & $4(14.8)$ & - & - \\
Public/civil servant & 85 & $18(21.2)$ & 1.6 & 0.44 \\
Student/pupil & 9 & $2(22.2)$ & 1.6 & 0.60 \\
artisans & 36 & $12(33.3)$ & 2.9 & 0.10 \\
Trading & 12 & $4(33.3)$ & 2.9 & 0.20 \\
Retired & 32 & $14(43.8)$ & 4.5 & 0.02 \\
Farming & 79 & $1(1.3)$ & - & - \\
Time of reporting & 102 & $51(50.0)$ & 78.0 & $<0.001$ \\
Within 24hrs & 159 & $27(17.0)$ & - & - \\
After 24hrs & 42 & $27(64.3)$ & 8.8 & $<0.001$ \\
Admission status & 109 & $8(7.3)$ & & - \\
Out-patient & 57 & $46(80.7)$ & - & $<.001$ \\
In-patient & & $12(16.2)$ & 52.8 & - \\
Type of injury & 74 & $6(20.7)$ & - & - \\
Close globe & $11(37.9)$ & 1.3 & 0.59 \\
Open globe & 29 & $21(37.5)$ & 3.1 & 0.020 \\
Place of injury & 29 & $0(0.0)$ & 3.1 & 0.007 \\
Home & 56 & $15(18.5)$ & - & - \\
School & & $18(43.9)$ & $6.5 \times 10^{7}$ & $<0.001$ \\
Road & 9 & $2.2 \times 10^{8}$ & $<0.001$ \\
Work-place & 81 & $4.3 \times 10^{8}$ & $<0.001$ \\
Agent of injury & 41 & &
\end{tabular}

${ }^{\ddagger} \mathrm{AOR}$ : adjusted odds ratio 
Factors within the groups that had the least likelihood of associating with poor visual outcomes were selected and included in a single logistic regression model to rank these factors in order of importance in predicting the final visual outcomes. These factors were first analysed using a multiple regression model to identify which of them had a significant effect on the dependent variable (visual outcome) and to be included in the logistic regression analysis. Results of the multiple regression analysis indicated that four factors: the initial visual acuity at the time of reporting, sustaining a closed globe injury, reporting to the hospital within a day of sustaining an injury, and having been managed medically without surgery had significant effects on the model. Results of the logistic regression analysis is presented in table 8, showing the relative positions of factors predicting a good final visual outcome.

Table 8: Relative importance of factors predicting final visual outcome

\begin{tabular}{lccc}
\hline \multirow{2}{*}{ Factor } & \multicolumn{3}{c}{ Final best corrected visual acuity of 6/18 or better } \\
\cline { 2 - 4 } & Relative odds & $95 \% \mathrm{Cl}$ & $\mathrm{p}$-value \\
\hline Initial visual acuity of 6/18 or better & 12.1 & $1.4-108.2$ & 0.026 \\
Reporting to the hospital within a day of injury & 9.0 & $2.2-37.2$ & 0.002 \\
Sustaining a closed globe injury & 8.9 & $1.8-43.1$ & 0.008 \\
Medical treatment only & 5.6 & $0.8-9.8$ & 0.091 \\
\hline
\end{tabular}

ฯCl: Confidence interval

\section{Associations between ocular tissues affected and visual outcomes}

All the affected tissues of the eye were again, included in a logistic regression model after being first analysed using a multiple regression analysis to identify those that had a significant effect on the final visual outcome. This was to determine which of the tissues' involvement was more important than others in predicting poor visual outcomes. Retina/choroid involvement was the most important factor to predict a poor visual outcome (Table 9).

Table 9: Associations between ocular tissues affected and final visual outcome

\begin{tabular}{lccc}
\hline \multirow{2}{*}{ Ocular tissue affected } & \multicolumn{3}{c}{ Final best corrected visual acuity of $6 / 60$ or worse } \\
\cline { 2 - 4 } & Relative odds & $95 \% \mathrm{Cl}$ & $\mathrm{p}$-value \\
\hline Retina/choroid & 53.3 & $13.7-210.8$ & $<0.001$ \\
Lens & 4.7 & $1.2-18.2$ & 0.024 \\
Cornea & 3.7 & $1.1-12.1$ & 0.025 \\
Iris & 3.7 & $1.2-11.5$ & 0.029 \\
\hline
\end{tabular}

ICl: Confidence interval

\section{Discussion}

The study sought to evaluate the epidemiology and visual outcomes of ocular injuries in Southern Ghana. The incidence of ocular injuries in this study (3.4\%) is lower than in a previous study at the Tamale Teaching hospital in Northern Ghana which reported an incidence of $17.8 \% .{ }^{9}$ The current result is, however, comparable to findings in Southwestern Nigeria $(4 \%)^{16}$ and Southern India $(4.0 \%)^{21}$. The discrepancies suggest differing levels of socioeconomic conditions such as availability and access to health care and industrialization. Notably, the incidence of ocular injuries appears to be higher in the industrialized countries such as the US $\left(19.8 \%\right.$ in Beaver Dam $^{22}, 14.4 \%$ in Baltimore $\left.{ }^{23}\right)$ and Australia $(21.1 \%)^{24}$ which may be due to industrial-related risk factors or better registration of injuries in these countries. 
Similar to the male to female ratio of 1.7:1 recorded in the present study, the study in Northern Ghana reported a ratio of $1.8: 1$. This ratio is also comparable to findings in Southwestern Nigeria $(2: 1)^{16}$ and rural South India (1.6:1) ${ }^{25}$ Some countries have reported relatively higher male to female ratio of 2.6:1 in the $\mathrm{US}^{26}$ and 3.3:1 in Turkey. ${ }^{27}$ The preponderance of ocular injury cases among males seems to be far beyond the influence of cultural and occupational factors. It is reported that even in occupations with higher numbers of female employees, males were still more likely to sustain ocular injuries. ${ }^{7}$ Further studies are required to fully comprehend these trends.

Late presentation to the health facility is known for complications and poor prognosis following ocular injuries especially in agriculture-related injuries in poor income societies. ${ }^{17}$ Presentation to the hospital within 24 hours after suffering ocular injuries as reported in this study (39.4\%), is similar to the study by Gyasi et $\mathrm{al}^{8}$ in the Upper East region of Ghana where 33.3\% presented within 24 hours. Comparable findings of late presentation have also been reported by Ajayi et $\mathrm{al}^{16}$ in Southwestern Nigeria, Yaya ${ }^{28}$ in the Central African Republic and Megbelayin ${ }^{29}$ in Calabar, Nigeria. These studies suggested that late presentation was due to long distances of health facilities from the patients. A study in Pakistan rather found that the time of presentation to the hospital was inversely related to the distance travelled where only $28.6 \%$ of the patients presented within 24 hours of injury. ${ }^{30}$ In the present study, distances travelled by patients were not assessed but reporting to the hospital after 24 hours was significantly associated with work-related injuries, sustaining a mechanical globe injury, and occupations that are usually associated with low levels of education. Omolase et $\mathrm{al}^{11}$ also reported that levels of education significantly affected the time of presentation.

Many studies have reported that ocular injuries occur predominantly among younger and middle aged individuals ${ }^{7,8,15,29}$ as found in the current study where the majority of the ocular injury patients were within the productive age of 20-29 years. Consequently, the ensuing visual loss has significant psychological, social and emotional implications. This younger population at risk also underscores the economic implications associated with loss of productivity. The workplace has been reported as the most common place where adults experience eye injuries. ${ }^{7}$ Likewise, in this study, the adults were more involved in ocular injuries at workplace (average age of 43 years), followed by on the road (average age of 30.8 years) and home (average age of 26.5years). The etiology of ocular injuries relating to the road raises concerns regarding injuries and mortalities resulting from road traffic accidents in Ghana which has been attributed to non-enforcement of road traffic regulations. ${ }^{31}$ It is reported that implementation of seat belt legislation and the use of redesigned airbags in vehicles have significantly reduced motor vehicle-related eye injuries in the UK and elsewhere. ${ }^{17}$

In terms of occupation, ocular trauma occurred commonly among school pupils or students. A similar observation was reported in the study in Northern Ghana by Bonsaana et $\mathrm{al}^{9}$ and in Egypt by Soliman et $\mathrm{al}^{32}$. Again, ocular injuries have previously been known to occur mostly at work due to work hazards and lack of safety. ${ }^{24,33,34}$ Recent trends, however, seem to suggest that the home has replaced the workplace as the location of greatest proportion of eye injuries, ${ }^{4,13,15,26,35}$, as recorded in the present study. This change in trend has been attributed in some jurisdictions to the increase in mandatory use of protective eye devices in the workplace, ${ }^{26}$ which has probably not been understood well in the home environment. There is the need to compile and enforce a comprehensive national legislation on mandatory use of protective eye devices as part of a general occupational eye safety and health programme. Even among high risk Ghanaian industrial workers such as miners and mechanics, there is a reported non-usage of protective eyewear. ${ }^{36,37}$

Comparable to our findings, the study by Gyasi et al ${ }^{8}$ in Northern Ghana reported higher improvement in visual acuities of $26.8 \%$ of patients after treatment. Omolase et $\mathrm{al}^{11}$ also reported a good prognosis for restoration of vision in most $(62.9 \%)$ patients after treatment. However, a study in KwaZulu-Natal, South Afri$\mathrm{ca}$, reported a reduction in visual acuities of patients of up to $37.7 \%$ following treatment of ocular injury. ${ }^{35}$ The fact that majority of the patients in the KwaZulu-Natal study had open globe injuries may account for the poor visual outcomes following treatment. In line with our finding that farmers were more likely to have poor visual outcomes following ocular injuries, Thylefors reported that injuries sustained in agricultural communities often led to rapidly progressing corneal ulceration and blindness. ${ }^{6}$ Ocular injuries resulting from farming activities mostly involve vegetation which are notori- 
ously harmful agents. ${ }^{18}$ In terms of ocular tissues affected, our findings are similar to a previous study that associated retinal and vitreous involvement with poor prognosis in ocular trauma. ${ }^{38}$

A limitation of this study was the poor documentation of patients' records resulting in some parameters being eliminated from the logistic regression model. The inclusion of these parameters may have broadened the perspectives of the findings. In conclusion, the incidence of ocular injuries in Southern Ghana was lower than that in the Northern part of the country, probably highlighting the differing socioeconomic conditions between the two locations. The study found majority of ocular injuries to occur in homes suggesting the need to improve the use of protective eye wear within this setting. General awareness about the safe use of domestic chemicals, kitchen equipment or gardening tools should be created to reduce the occurrence of ocular injuries at homes.

\section{Funding sources}

None declared.

\section{Acknowledgements}

Due acknowledgement is made to the staff at the eye clinic of the Cape Coast Teaching Hospital for their cooperation and support towards this work.

\section{Conflict of interest}

None declared.

\section{References}

1. Chen G, Sinclair SA, Smith GA, Ranbom L, Xiang H. Hospitalized ocular injuries among persons with low socioeconomic status: a medicaid enrollees-based study. Ophthalmic Epidemiol. 2006;13:199-207

2. Cillino S, Casuccio A, Di Pace F, Pillitteri F, Cillino G. A five-year retrospective study of the epidemiological characteristics and visual outcomes of patients hospitalized for ocular trauma in a Mediterranean area. $B M C$ Ophthalmol. 2008; 8: 6

3. Abraham DI, Vitale SI, West SI, Isseme I. Epidemiology of eye injuries in rural Tanzania. Ophthalmic Epidemiol. 1999; 6: 85-94

4. Khan AK. Ocular injury: Prevalence in different rural population of Bangladesh. Bangladesh Med Res Counc Bull. 2013; 39:130-138

5. Négrel AD, Thylefors B. The global impact of eye injuries. Ophthalmic Epidemiol. 1998; 5: 143-169

6. Thylefors B. Epidemiological patterns of ocular trauma. Aust N Z J Opbthalmol. 1992; 20: 95-98
7. Sukati VN. Workplace eye injuries: a literature review. Occupational Health Southern Africa. 2014; 20: 18-22

8. Gyasi ME, Amoaku WM, Adjuik MA. Epidemiology of hospitalized ocular injuries in the upper east region of Ghana. Ghana Med J. 2007; 41:171-175

9. Bonsaana GB, Nyenze EM, Ilako DR, Wanye S. Review of ocular trauma in Tamale Teaching Hospital, Tamale, Ghana. J Opbthalmol Eastern Central Southern Afr (JOECSA). 2015;19: 75-81

10. Patel D. Eye injuries: improving our practice. Comm Eye Health J. 2015; 28: 41-43

11. Omolase CO, Omolade EO, Ogunleye OT, Omolase BO, Ihemedu CO, Adeosun OA. Pattern of ocular injuries in Owo, Nigeria. J Ophthalmic Vis Res. 2011; 6: 114-118

12. Onakpoya OH, Adeoye A, Adeoti CO, Ajite K. Epidemiology of ocular trauma among the elderly in a developing country. Ophthalmic Epidemiol. 2010:17;315-320 13. Puodžiuvienè E, Jokūbauskienè G, Vieversyte M, Asselineau K. A five-year retrospective study of the epidemiological characteristics and visual outcomes of pediatric ocular trauma. BMC Ophthalmol. 2018; 18:10

14. Sengupta P, Mazumdar M, Gyatsho J. Epidemiology of ocular trauma cases presenting to a tertiary care hospital in a rural area in West Bengal, India over a period of 2 years. IOSR J Dent Med Sci (IOSRJDMS). 2016; 15: 92-97

15. Mallika PS, Tan AK, Asok T, Faisal HA, Aziz S, In$\tan$ G. Pattern of ocular trauma in Kuching, Malaysia. Malays Fam Physician. 2008; 3:140 -145

16. Ajayi IA, Ajite KO, Omotoye OJ. Epidemiological survey of traumatic eye injury in a Southwestern Nigeria tertiary hospital. Pak J Ophthalmol. 2014; 30:137-141 17. Pradhan E. Ocular trauma: prevention. Nepal J Ophthalmol. 2016; 8: 107-109

18. Stein HA, Stein RM, Freeman MI. 8th ed. The Ophthalmic Assistant: A Text for Allied and Associated Ophthalmic Personnel. St Louis, MO: Elsevier Mosby, 2006.

19. Ghana Statistical Service. Population and housing census summary report of final results, Ghana Statistical Service, Accra, Ghana, 2012.

20. World Health Organization. International Statistical Classification of Diseases and Related Health Problems. 10th Revision, 2nd ed. Geneva: World Health Organization, 2005.

21. Dandona L, Dandona R, Srinivas M, John RK, McCarty CA, Rao GN. Ocular trauma in an urban population in southern India: the Andhra Pradesh Eye Disease Study. Clin Exp Ophthalmol. 2000; 28: 350-356

22. Wong TY, Klein BE, Klein R. The prevalence and 
5-year incidence of ocular trauma1: The Beaver Dam Eye Study. Ophthalmol. 2000; 107: 2196-2202

23. Katz J, Tielsch JM. Lifetime prevalence of ocular injuries from the Baltimore Eye Survey. Arch Ophthalmol. 1993; 111:1564-1568

24. McCarty CA, Fu CL, Taylor HR. Epidemiology of ocular trauma in Australia. Ophthalmology. 1999; 106:1847-1852

25. Nirmalan PK, Katz J, Tielsch JM, Robin AL, Thulasiraj RD, Krishnadas R et al. Ocular trauma in a rural south Indian population: the Aravind Comprehensive Eye Survey. Ophthalmology. 2004; 111:1778-1781

26. May DR, Kuhn FP, Morris RE, Witherspoon CD, Danis RP, Matthews GP et al. The epidemiology of serious eye injuries from the United States Eye Injury Registry. Graefes Arch Clin Exp Ophthalmol. 2000; 238:153-157

27. Soylu M, Sizmaz S, Cayli S. Eye injury (ocular trauma) in southern Turkey: epidemiology, ocular survival, and visual outcome. Int Ophthalmol. 2010; 30:143-148 28. Yaya G, Bobossi GS, Gaudeuille A. Ocular injuries in children aged 0-15 years: epidemiological and clinical aspects at the Bangui National Teaching Hospital. J Fr Ophthalmol. 2005; 28: 708-712

29. Megbelayin EO, Nkanga DG, Ibanga A, Okonkwo SN. Pattern and causes of ocular injuries in Calabar, cross river state, Nigeria. J Trauma Care. 2016; 2:10-14

30. Qureshi MB. Ocular Injury pattern in Turbat, Bal- uchistan, Pakistan. Comm Eye Health J. 1997;10:57-58 31. Coleman A. Road traffic accidents in Ghana: a public health concern, and a call for action in Ghana, (and the Sub-Region). Open J Prev Med. 2014; 4: 822-828

32. Soliman MM, Macky TA. Pattern of ocular trauma in Egypt. Graefes Arch Clin Exp Ophthalmol.2008; 246:205-212

33. Smith ARE, O'Hagan SB, Gole GA. Epidemiology of open- and closed-globe trauma presenting to Cairns Base Hospital, Queensland. Clin Exp Ophthalmol. 2006; 34: 252-259

34. Wong TY, Tielsch JM. A population-based study on the incidence of severe ocular trauma in Singapore. Am J Ophthalmol. 1999;128: 345-351

35. Sukati V, Hansraj R. A retrospective analysis of eye injuries in rural KwaZulu-Natal, South Africa. $S$ Afr Optom. 2012; 71: 159-165

36. Abu EK, Boadi-Kusi SB, Quarcoo PO, Kyei S, Owusu-Ansah A, Darko-Takyi C. Ocular health and safety assessment among mechanics of the Cape Coast Metropolis, Ghana. J Ophthalmic Vis Res. 2016;11:78-83. 37. Ocansey S, Ovenseri Ogbomo GO, Abu EK, Kyei S, Boadi Kusi SB. Self-reported eye disorders and visual hazards among Ghanaian mine workers. J Med Biomed Sci. 2012;1:37 45

38. Brinton GS, Aaherg TM, Resser FH, Topping TM, Abrams GW. Surgical results in ocular trauma involving the posterior segment. Am J Ophthalmol. 1982; 93: 271278 